NASA CONTRACTOR REPORT 189572

\title{
MECHANICAL PROPERTIES OF TRIAXIALLY BRAIDED COMPOSITES: EXPERIMENTAL AND ANALYTICAL RESULTS
}

John E. Masters and Raymond L. Foye Lockheed Engineering and Sciences Company Hampton, VA

and

Christopher M. Pastore and Yasser A. Gowayed North Carolina State University

Contract NAS1-19000 January 1992

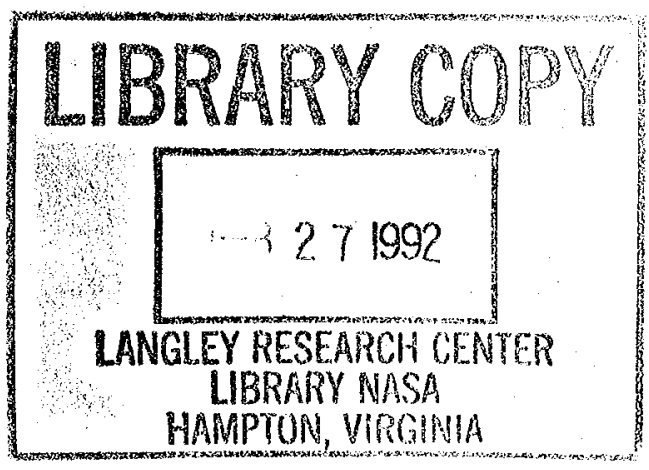

National Aeronautics and Space Administration

LANGLEY RESEARCH CENTER Hampton, Virginia 23665-5225

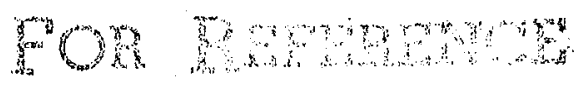




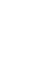




\title{
Mechanical Properties of Triaxially Braided Composites: Experimental and Analytical Results
}

\author{
John E. Masters, \\ Lockheed Engineering and Science \\ Raymond L. Foye, \\ Lockheed Engineering and Science \\ North Carolina A \& $T$ State University \\ Christopher M. Pastore, \\ a $\mathbf{n}$ \\ Yasser A. Gowayed \\ North Carolina State University
}

\begin{abstract}
This paper investigates the unnotched tensile properties of 2-D triaxial braid reinforced composites from both an experimental and an analytical viewpoint. The materials are graphite fibers in an epoxy matrix. Three different reinforcing fiber architectures were considered. Specimens were cut from RTM composite panels made from each braid. There were considerable differences in the observed elastic constants from different size strain gage and extensometer readings. Larger strain gages gave more consistent results and correlated better with the extensometer readings. Experimental strains correlated reasonably well with analytical predictions in the longitudinal, $0^{\circ}$, fiber direction but not in the transverse direction. Tensile strength results were not always predictable even in reinforcing directions. Minor changes in braid geometry led to disproportionate strength variations.

The unit cell structure of the triaxial braid was discussed with the assistance of computer analysis of the microgeometry. Photomicrographs of braid geometry were used to improve upon the computer graphics representations of unit cells. These unit cells were used to predict the elastic moduli with various degrees of sophistication. The simple and the complex analyses were generally in agreement but none adequately matched the experimental results for all the braids.
\end{abstract}




\section{INTRODUCTION}

Braid reinforced composites are one of the many textile fabric reinforced composites that are under consideration as lower cost and higher impact resistant/tolerant materials for aircraft applications. The wide variety of crosssectional forms that can be braided promises to reduce fabrication costs for standard and custom made stiffeners, truss members, rotor blade spars, longerons, and frames. However, the analytical tools to evaluate these materials are just now being developed and reliable data bases of fundamental properties are incomplete. Both of these needs are addressed in this investigation.

The specific objective of this study was to understand the role of the braid reinforcement microgeometry in laminate mechanical behavior. This was accomplished through combined analytical and experimental efforts. Fabric preforms were modelled using a process science model. Cured laminates were investigated and their fabric geometries were characterized. The materials' mechanical properties were experimentally measured in unnotched tensile tests and compared to predictions made using analytical models.

A series of three 2-D triaxial braid geometries were investigated in this study. The specimens, which were designed by Boeing and supplied to NASA Langley as part of a joint NASA-Boeing investigation, had a $0 / \pm \theta$ braid pattern. The materials' Young's moduli, Poisson's ratios, and ultimate strengths were experimentally determined under in-plane tension load. The sensitivity of these measurements to strain gage size was also studied.

The architecture of the fibers is the key to understanding the mechanical behavior of textile composites. The fabric geometry controls the material response. It must be well understood to interpret the experimental data. Similarly, the ability of any material model to predict material behavior hinges upon the accuracy of its treatment of the fiber geometry.

Graphical modelling of the braided unit cell was carried out using a processing science model coupled with a graphical rendering on a personal computer. This approach permits the construction of a mathematical representation of the surfaces and orientations of the braided yarns within the composite material. The geometric description of the unit cell was validated through optical microscopy and the model was updated to incorporate secondary fabrication effects. Based on the definition of fiber architecture provided by the process science model, it is possible to characterize material properties in local regions within the unit cell. 
The analysis of braids is usually based on the use of either a simple diagonal brick model or a more complex inhomogeneous finite element model. Each approach was applied to predict the Young's moduli and the Poisson's ratios of the braided material. In addition, the application of a laminated plate model to these materials was investigated as a simple approximation tool.

\section{MATERIAL SYSTEMS}

The materials employed in this study featured triaxially braided AS-4 fabric impregnated with Shell 1895 epoxy resin. A triaxially braided fabric, as shown schematically in Figure 1 , consists of three yarns, $0^{\circ}, \pm \theta^{\circ}$, intertwined in a single layer. The fabrics studied were braided in a $2 / 2$ pattern. That is, a $+\theta$ braided tow continuously passes over two $-\theta$ tows and then under two $-\theta$ tows and vice versa. The $0^{\circ}$ or longitudinal tows are introduced into the fabric during braiding through stationary guide eyes. These tows are straight (without crimp) and are parallel to the braid axis. Note, the gaps shown between fibers in this schematic are exaggerated for clarity in illustrating the braid pattern.

Three braid geometries were investigated. The braid angle, the yarn sizes, and the longitudinal yarn content were varied to assess material sensitivity to these parameters. The last parameter listed is typically expressed as percentage of $0^{\circ}$ yarns. It is the volumetric proportion of longitudinal yarns to total yarn content and is a function of braid angle and yarn size. Yarn size is expressed in terms of the number of filaments per yarn. The longitudinal yarns were larger than the braider yarns in all cases.

The nominal braid configurations are summarized in Table I. In addition to the three parameters listed above, the table also lists the nominal spacings of the longitudinal and braid yarns. Both quantities are expressed in terms of yarn per inch.

Table I. Triaxial Braid Configurations

\begin{tabular}{|c|c|c|c|c|c|c|}
\hline MATERIAL & $\begin{array}{c}\text { BRAID } \\
\text { PATTERN }\end{array}$ & $\begin{array}{c}\text { BRAIDER } \\
\text { YARN SIZE } \\
\text { (Fiber No.) }\end{array}$ & $\begin{array}{c}0^{\circ} \text { YARN } \\
\text { SIZE } \\
\text { (Fiber No.) }\end{array}$ & $\begin{array}{l}\text { PERCENT } 0^{\circ} \\
\text { YARNS (\%) }\end{array}$ & $\begin{array}{c}0^{\circ} \text { YARN } \\
\text { SPACING } \\
\text { (Yarn/in.) } \\
\end{array}$ & $\begin{array}{c}\text { BRAID YARN } \\
\text { SPACING } \\
(\text { Yarn/in.) } \\
\end{array}$ \\
\hline $\mathrm{Al}$ & $0 / \pm 63^{\circ}$ & $12 \mathrm{~K}$ & $24 K$ & 31.5 & 4.17 & 9.16 \\
\hline B1 & $0 / \pm 66.5^{\circ}$ & $6 \mathrm{~K}$ & $18 \mathrm{~K}$ & 37.6 & 4.77 & 11.98 \\
\hline B2 & $0 / \pm 70^{\circ}$ & $6 \mathrm{~K}$ & $18 \mathrm{~K}$ & 34.0 & 4.37 & 12.74 \\
\hline
\end{tabular}

Note: $K$ indicates thousands. For the AS-4 yarns, fiber diam. equals 7 microns. 


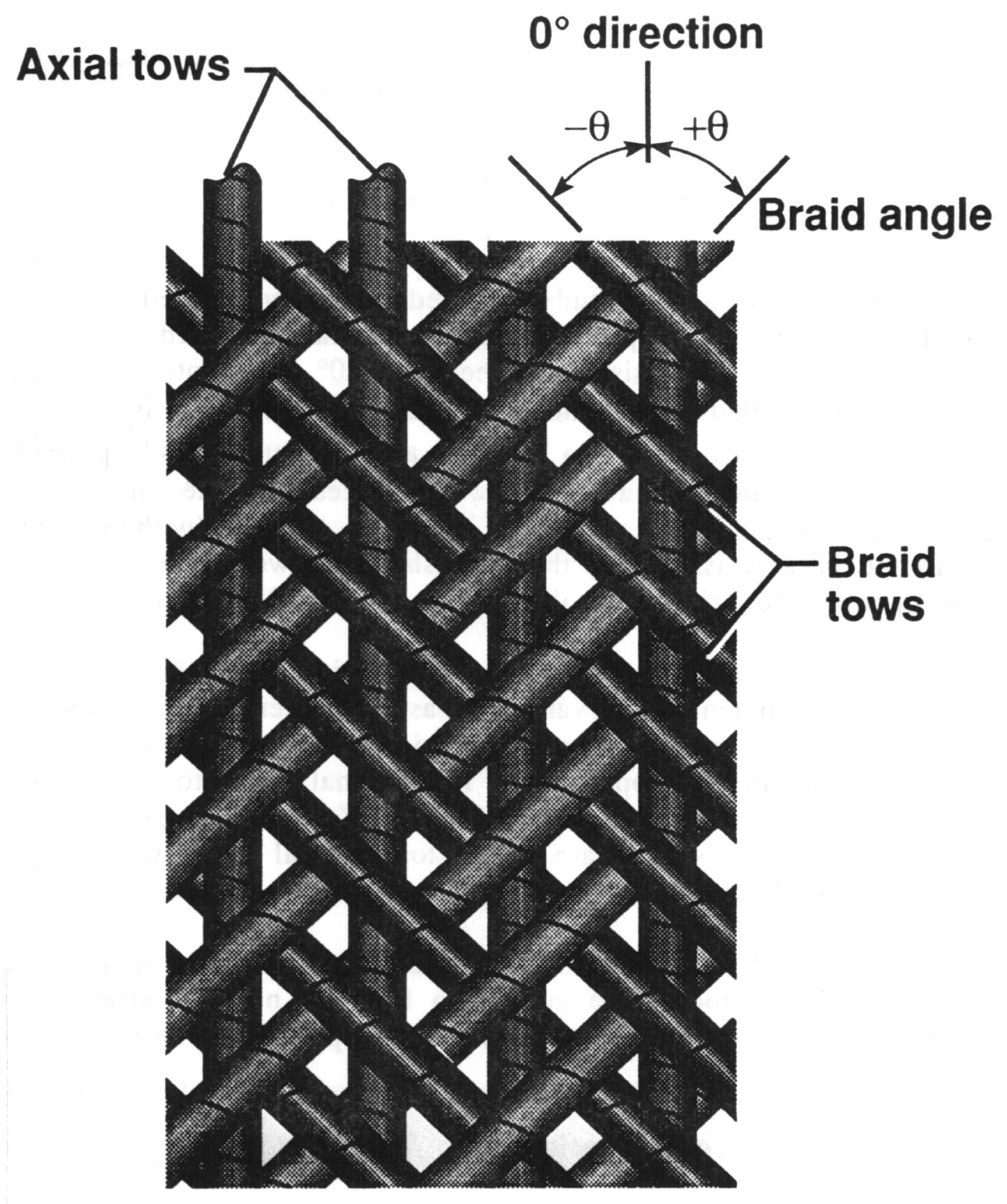

Figure 1. Triaxial braid pattern. 
The fabrics investigated in this study were formed with a 144 carrier New England Butt triaxial braider, incorporating 72 longitudinal yarns in a $2 / 2$

regular braid pattern. The braids were formed on cylindrical mandrels, and the desired preform thickness was achieved by over-braiding layers. Since all specimens were to have a nominal thickness of 0.125 in., the number of layers increased as yarn bundle size decreased. Mandrel diameter, D, was also increased to vary longitudinal yarn content.

Table II summarizes the processing parameters employed for each architecture.

\section{Table II. Braid Processing Parameters}

\begin{tabular}{c|cc} 
MATERIAL & NUMBER OF LAYERS & $\begin{array}{c}\text { MANDREL DIAM. } \\
\text { (in.) }\end{array}$ \\
\hline \hline A 1 & 4 & 5.5 \\
B1 & 5 & 4.8 \\
B2 & 5 & 5.25
\end{tabular}

After braiding, the fabric was cut longitudinally, removed from the mandrel, and border stitched to maintain handleability. The resulting flat pieces of layered fabric were placed in molds and resin was applied through a resin transfer molding (RTM) process.

The braid configurations listed in Table I can be related to the braid process parameters described in the previous paragraphs through mathematical models. A process science model [1] is being developed to relate braid pattern to machine parameters. It also provides a mathematical description of the fiber architecture. This latter aspect of the model will be discussed in the next section, Geometric Modelling.

The models developed to date, however, are approximate because they cannot account for all secondary manufacturing effects which can alter braid architecture. Empirical data, gathered from cured laminates, is required to update these models.

The final fiber architectures of the three braid types were experimentally characterized. The laminates' braid angles, percentage of longitudinal fibers, fiber content, resin content, and their thicknesses were determined. 
Digital images of sample specimens from the composite panels were produced and image analysis software was used to calculate braid angles. Each braid was formed with one carrier supplying a nickle coated graphite yarn for post-manufacturing optical and $\mathrm{X}$-ray investigation of the fabric and composite. These yarns were used to verify the placement of yarns in the structure.

Figure 2 shows a scanned image of a typical braided specimen. The nickle coated AS-4 is clearly visible in this scanned image. Samples from different architectures and different panels of the same architecture were scanned for quantification. By tracing the nickle coated yarn, the braid angle was measured for each of the specimens examined. The variation of the braid angle within panels was negligible; the variation of braid angle between panels was found to be less than $1^{\circ}$.

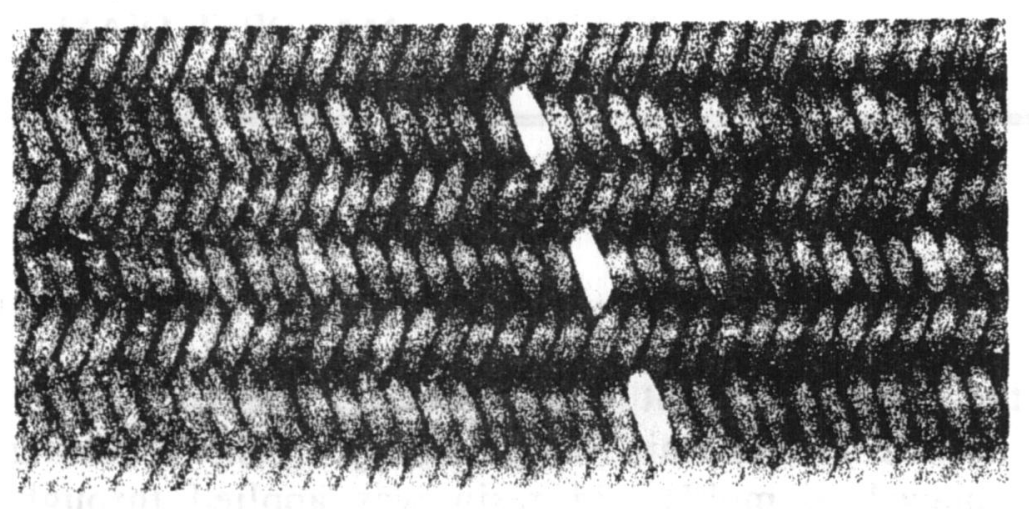

Figure 2. Scanned Surface of Braided Composite Specimen (Type B1) Showing Nickle Coated AS-4 Yarn in Braider Position.

Internal fiber architecture was examined by sectioning and polishing samples of the material. Cross-sectional photomicrographs of the various specimens were also scanned into the computer and examined to determine the placement and frequency of longitudinal yarns. Additionally, the shape of the yarn cross-sections, longitudinal and braid yarn curvatures, and interstitial areas were assessed. Finally, the thickness of the composites were also measured from these micrographs.

The photomicrograph in Figure 3 shows the cross-section of a specimen made from the $\mathrm{B} 2$ material. The specimen has been sectioned along the $0^{\circ}$ yarns. The three bright horizontal bands that traverse the photomicrographs are sections of axial yarns that intersect the polished surface. The $0^{\circ}$ yarns in the two remaining layers did not intersect this plane. The figure illustrates that the inserted $0^{\circ}$ yarns exhibit no crimp and are quite straight. Figure 4 contains a 


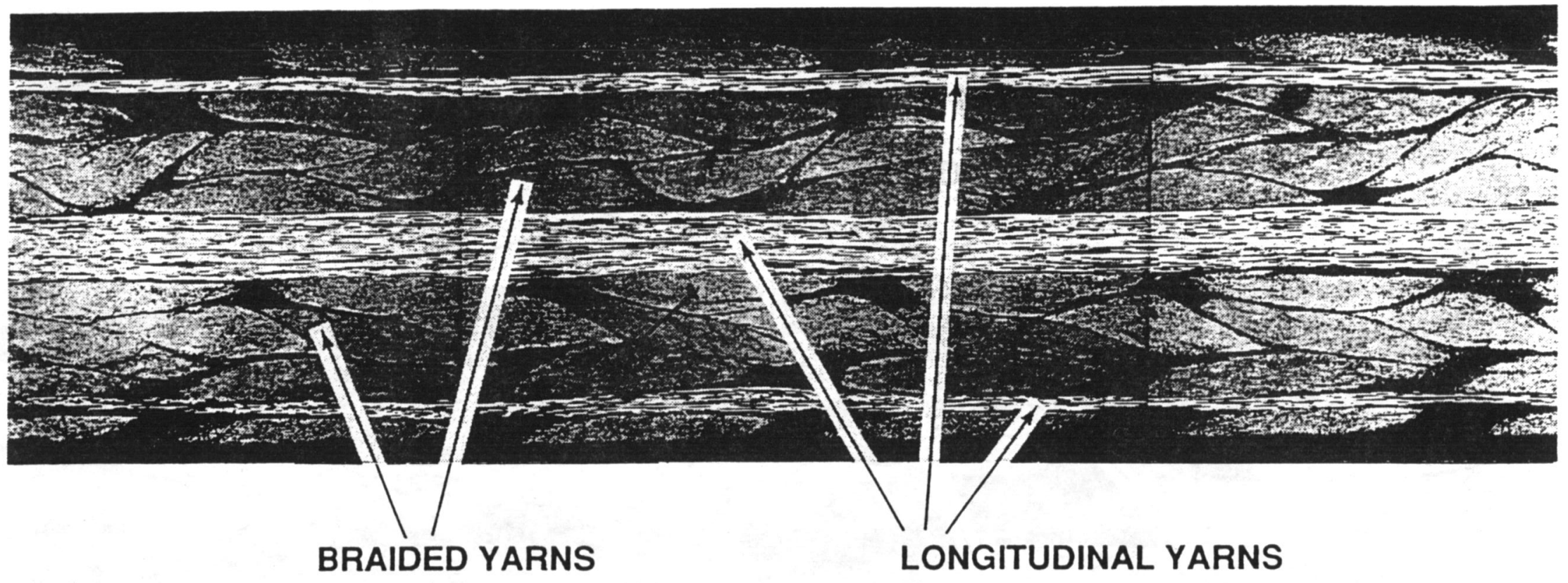

Figure 3. Longitudinal cross-section (20X) of a B2 laminate. 


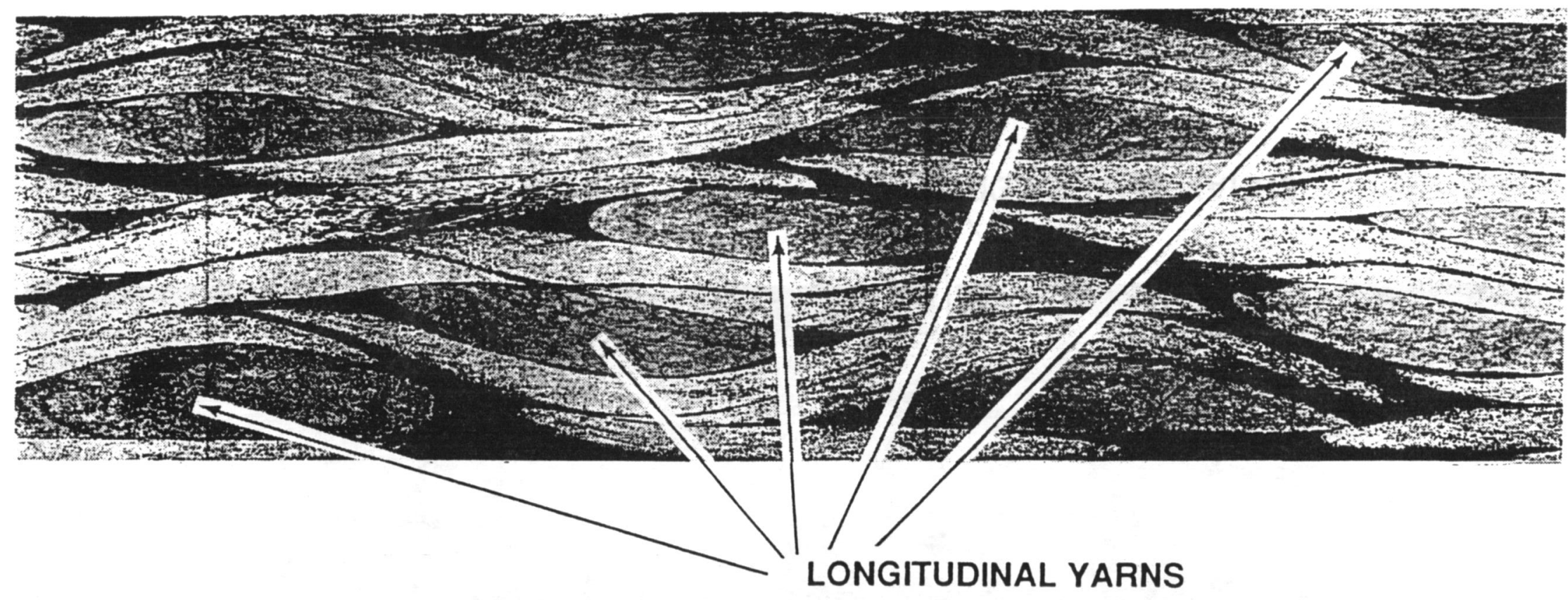

Figure 4. Transverse cross-section (20X) of a B2 laminate. 
All five layers of braided preform material can be identified in the figure. The photomicrograph indicates that the axial yarns do not stack on top of one arother. Instead, the layers of material nest during the braiding operation. For this reason, only three axial yarns are visible in Figure 3. Finally, the photomicrograph shown in Figure 5 shows the cross-section of a B2 laminate that has been sectioned along the braided yarns. As in the case of the axial yarns, braided yarns for each layer do not appear. The degree of crimp developed in the braided yarns as they intertwine is illustrated in the figure.

The measured braid angles, frequency of longitudinal fibers, and the laminate thicknesses were input to the process science model. The materials' fiber volume fractions and their percentages of longitudinal fibers were predicted with this model using the description of the braiding process as input. The results of the observations and calculations are summarized in Tables III and IV. The physical characteristics and the fiber and resin content were not measured for all panels.

\section{Table III. Physical Characteristics of Test Panels}

\begin{tabular}{c|cccc} 
MATERIAL & $\begin{array}{c}\text { PANEL } \\
\text { NUMBER }\end{array}$ & $\begin{array}{c}\text { THICKNESS } \\
\text { (in.) }\end{array}$ & $\begin{array}{c}\text { BRAID ANGLE } \\
\left({ }^{\circ}\right)\end{array}$ & $\begin{array}{c}\text { PERCENT 0 } \\
\text { YARNS (\%) }\end{array}$ \\
\hline A1 & $15 \mathrm{~L}$ & .135 & 62.2 & 31.8 \\
& $1 \mathrm{U}$ & .137 & 62.4 & 31.7 \\
B1 & $2 \mathrm{~L}$ & .136 & 67.1 & 36.8 \\
& $4 \mathrm{U}$ & .126 & 67.7 & 36.3 \\
B2 & $10 \mathrm{~L}$ & .139 & 68.3 & 35.7 \\
& $11 \mathrm{~L}$ & .137 & 67.5 & 36.5
\end{tabular}

No significant differences were noted between the nominal braid configurations (Table I) and the measured and calculated physical properties listed in Table III. The braid angles and the ratio of longitudinal yarns to total yarn content showed only minor variations from the nominal values.

Though not listed in the table, the longitudinal yarn spacing was also measured from the photomicrographs. Comparing the measured values to the theoretical yarn spacings listed in Table I indicates negligible lateral expansion/contraction occurred during handling of the cut fabric.

Fiber volume fraction was predicted by the process science model and measured experimentally on specimens cut from the same panels used for tensile test coupons. Experimental measures of fiber and resin content were 


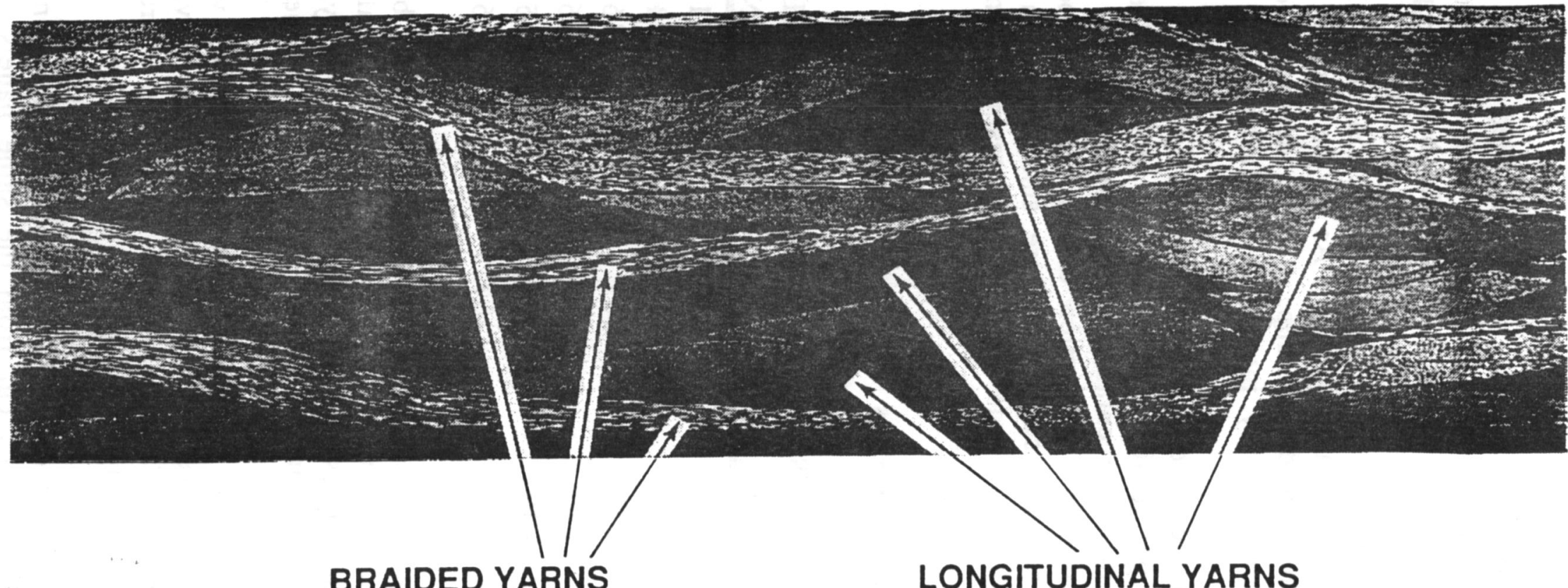

Figure 5. Cross-section of B2 laminate sectioned along braid yarns (20X). 
conducted in accordance with ASTM D-3171 [2]. Using this procedure, material samples were digested using concentrated sulfuric acid and $30 \%$ hydrogen peroxide. The weight fractions were measured and volume fractions calculated on the basis of density. The density value used for AS-4 was $1.80 \mathrm{~g} / \mathrm{cc}$ and for the resin was $1.18 \mathrm{~g} / \mathrm{cc}$. These results are summarized in Table IV along with the predicted fiber volume fractions.

Table IV. Laminate Fiber and Resin Content

\begin{tabular}{c|c|c|c|c|cc} 
MATERIAL & $\begin{array}{c}\text { PANEL } \\
\text { NUMBER }\end{array}$ & $\begin{array}{c}\text { DENSITY } \\
(\mathrm{g} / \mathrm{cc})\end{array}$ & $\begin{array}{c}\text { THICKNESS } \\
(\mathrm{in} .)\end{array}$ & $\begin{array}{c}\text { RESIN } \\
\text { VOL. } \\
(\%)\end{array}$ & $\begin{array}{c}\text { FIBER VOLUME } \\
\text { Measured } \\
(\%)\end{array}$ & $\begin{array}{c}\text { Predicted } \\
(\%)\end{array}$ \\
\hline \hline $\mathrm{A} 1$ & $1 \mathrm{U}$ & 1.51 & .137 & 45.7 & 54.0 & 54.5 \\
& $6 \mathrm{~L}$ & 1.51 & .137 & 45.6 & 54.0 & - \\
$\mathrm{B} 1$ & $2 \mathrm{~L}$ & 1.48 & .136 & 52.8 & 48.2 & 50.4 \\
& 3U & 1.50 & .127 & 47.4 & 52.3 & - \\
$\mathrm{B} 2$ & $4 \mathrm{U}$ & 1.50 & .126 & 46.7 & 52.8 & 55.9 \\
& $11 \mathrm{~L}$ & 1.48 & .137 & 50.9 & 48.9 & 46.3 \\
& $11 \mathrm{U}$ & 1.52 & .124 & 44.7 & 55.2 & -
\end{tabular}

As Tables III and IV indicate, the B1 and B2 materials exhibited a significant panel to panel variation in thickness. Their braid angles and the frequencies of their longitudinal yarns, however, remained relatively constant from panel to panel. Since the fiber preforms did not vary from plate to plate, the thinner laminates contained the same amount of fiber (as the thicker laminates) but less resin. This is reflected in the thinner laminate's lower resin volume percent and, conversely, in their higher fiber volume percent. Consequently, the fiber volume fraction of each individual panel needs to be determined before carrying out analytical modelling.

The correlation between thickness and resin content for panels with the same architecture is apparent. The process science model accurately predicts the fiber volume.

The data in Tables III and IV demonstrate the importance of characterizing material microstructure. Although the braided preforms seem consistent from panel to panel, variations in the RTM process altered the panels' resin content and changed their fiber volume. Since fiber and resin content effect the material's mechanical response, they should be measured for each panel tested and accounted for in predicting mechanical response. 


\section{GEOMETRIC MODELLING}

An accurate description of the fiber architecture is required to predict the mechanical properties of textile reinforced composites. The process science model noted earlier provides a three dimensional geometric model of the braided reinforcement. It is used as a front end to other analytical models which predict the materials mechanical properties.

The approach to the geometric modelling consists of three principal steps: i) construction of mean centerline points for each yarn, ii) smoothing the centerlines with a B-spline interpolation to construct a smooth and minimum strain energy curve, and iii) constructing a three dimensional object by sweeping a cross-section along the centerline and forming a surface.

The construction of the mean centerline was carried out on the basis of the processing science model which predicts the ideal architectural arrangement. Since the model cannot account for all secondary manufacturing effects, measured values (braid angle, thickness, distribution of longitudinal yarns, yarn cross-sectional geometry) were used to modify the predicted values. This update creates a good approximation of the actual geometry. Discrepancies between predicted geometries and actual geometries are eliminated prior to performing the mechanical analysis.

Figures 6-8 show the rendered graphics for architectures $\mathrm{A} 1, \mathrm{~B} 1$, and $\mathrm{B} 2$ respectively. The figures are not drawn to scale.

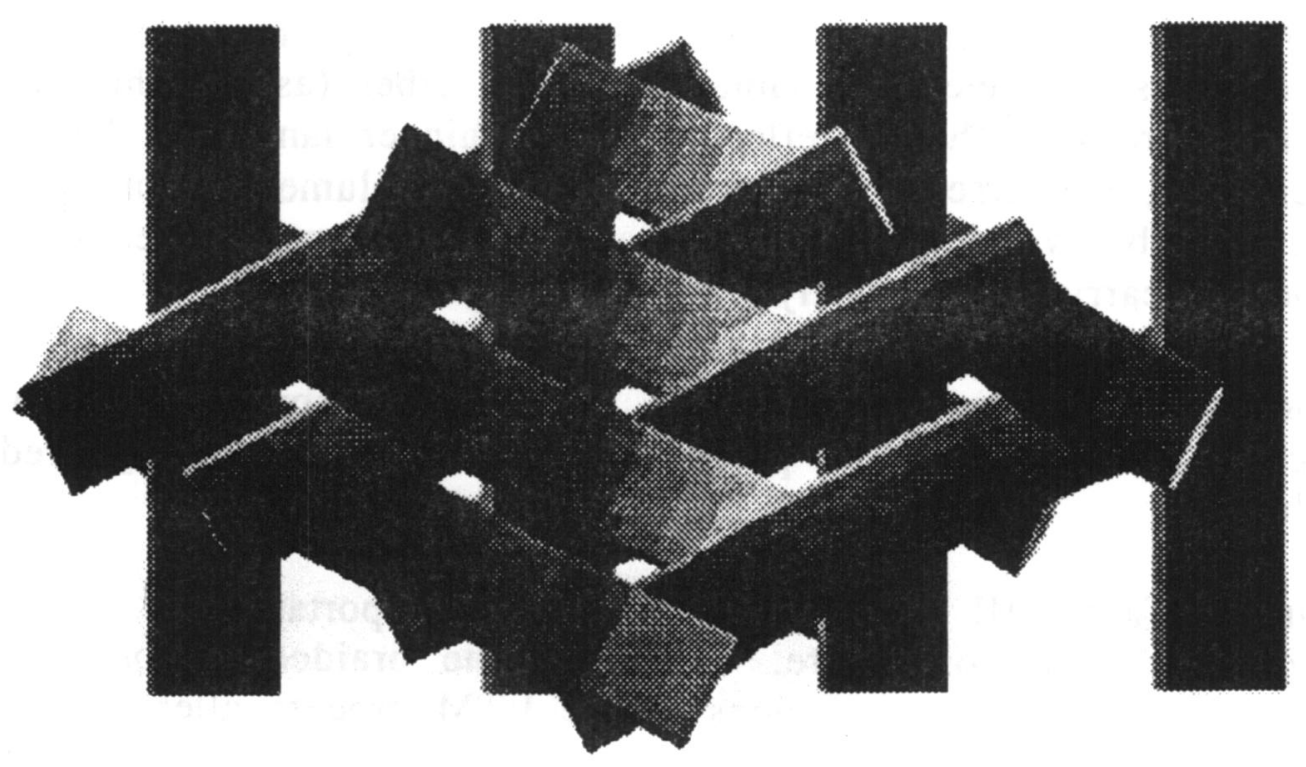

Figure 6. Graphical Rendering of Braid Architecture A1. 


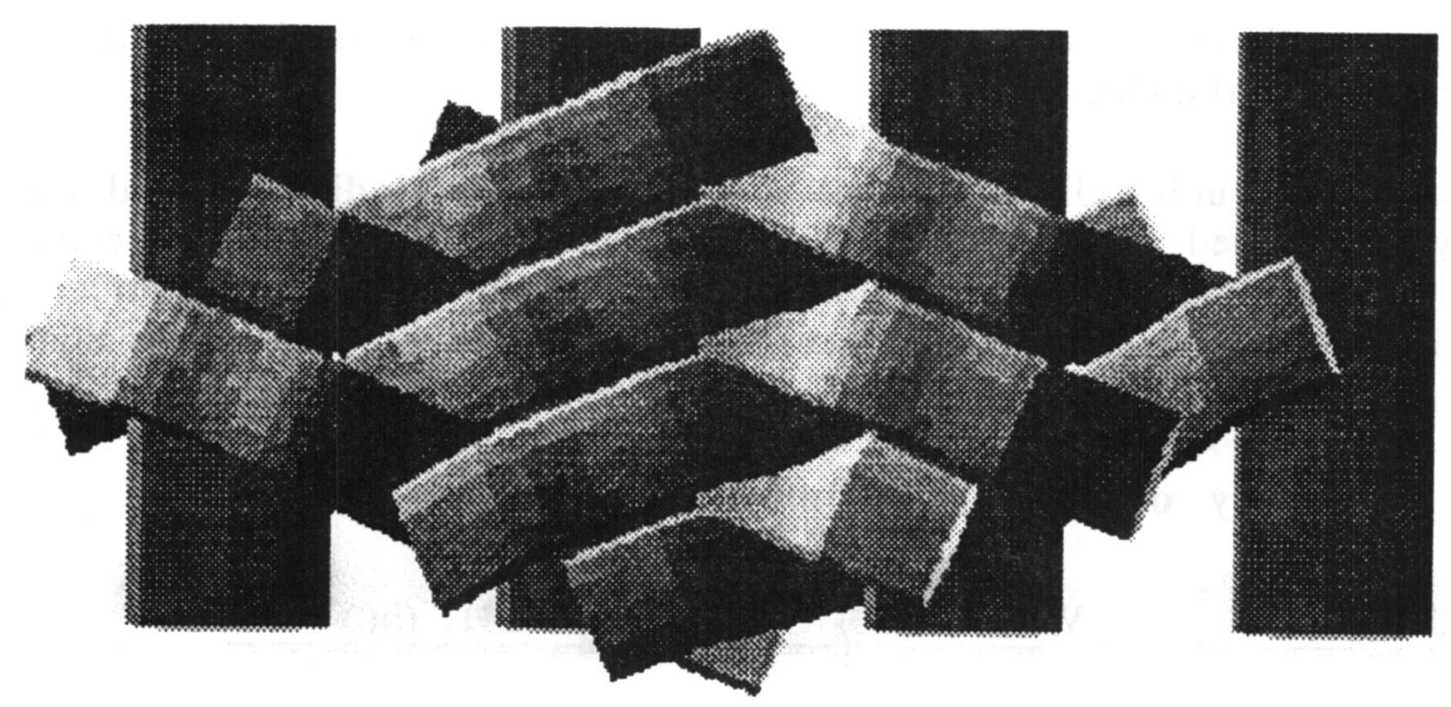

Figure 7. Graphical Rendering of Braid Architecture B1

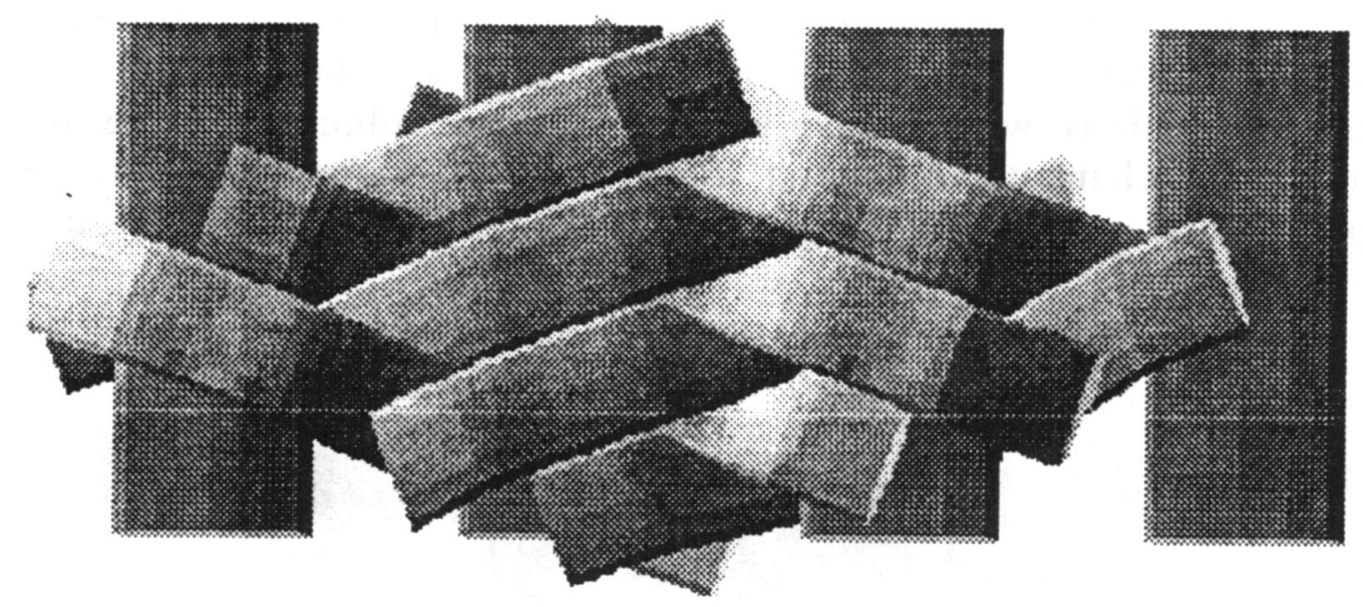

Figure 8. Graphical Rendering of Braid Architecture B2

The graphics can be validated in terms of braid angle, percent longitudinal tows, and fiber volume fraction. In the cases presented above, the renderings were formed based upon these measured values, thus the fit is excellent.

The rhombic frames shown in these figures define unit cells of the three braids studied. A unit cell is a repeatable unit of fabric geometry. It represents the complete yarn or tow intertwinement pattern. It is desirable, for analysis purposes, to define the smallest unit cell possible. Rectangular unit cells are also 
preferable. Figure 9 shows the smallest unit cell for a $2 / 2$ triaxial braid. It is contained within the rhombic unit cell.

In a braid, the unit cell width is dependent on mandrel diameter and the number of yarns braided. The height of the unit cell is dependent on the cell width and the braid angle. The sizes of the minimum unit cells for the three braids tested are summarized in Table V. The significance of these dimensions, particularly the width will be discussed further in the following section.

Table V. Summary of Minimum Unit Cell Sizes.

\begin{tabular}{c|cc} 
MATERIAL & WIDTH (in.) & HEIGHT (in.) \\
\hline \hline A 1 & 0.48 & 0.12 \\
B1 & 0.42 & 0.09 \\
B2 & 0.46 & 0.08
\end{tabular}

In addition to the graphic capability illustrated above, the code provides a numerical description of the reinforcing architecture. It is capable of sectioning tile unit cells into arbitrarily small volumes and examining the material orientations and proportions within each volume. These volumes can be recombined using finite elements to predict the mechanical response of the unit cell and to predict the mechanical properties of the braided composite structure [3].

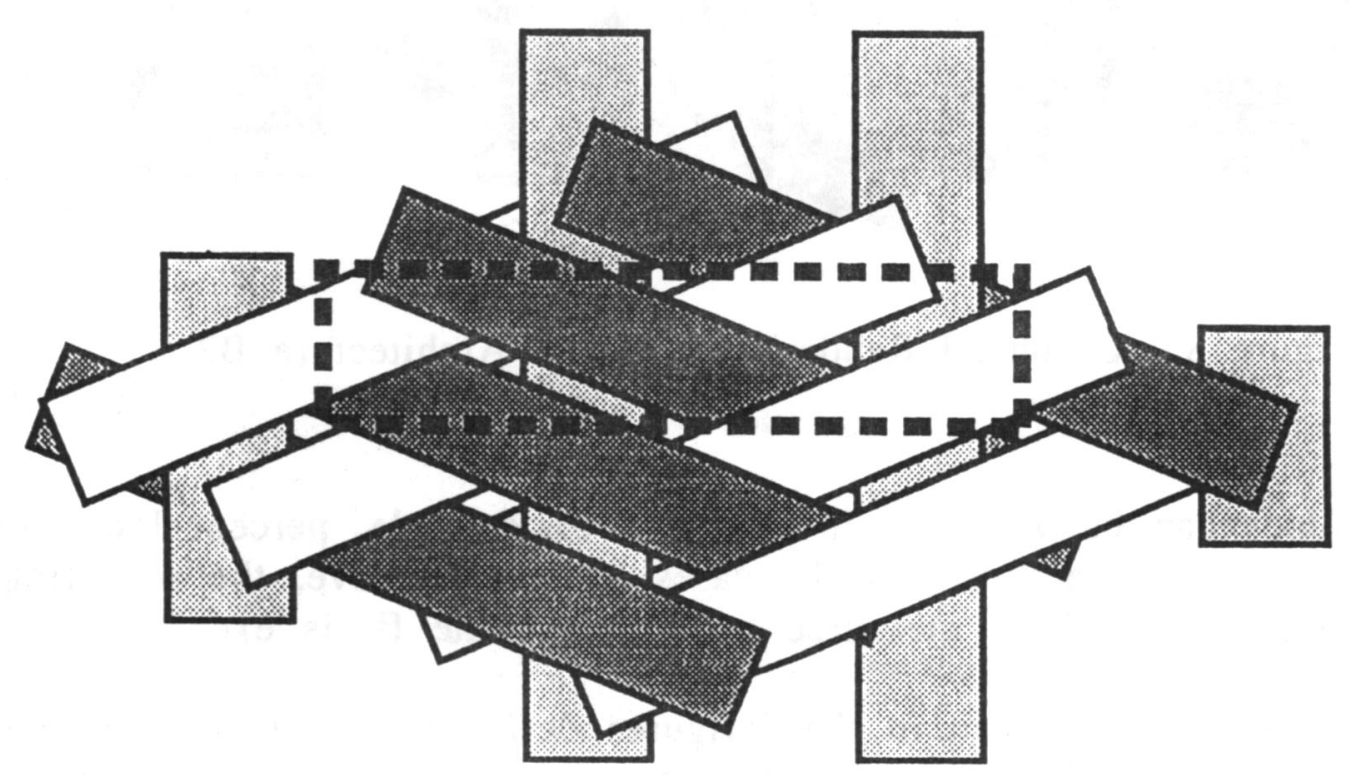

Figure 9. Smallest Unit Cell 


\section{EXPERIMENTAL RESULTS}

The mechanical properties of the three material systems were experimentally determined in a series of unnotched tensile tests. Test panels were fabricated and machined to permit direct determination of the materials' performance in both the longitudinal direction (parallel to the $0^{\circ}$ yarns) and the transverse direction (perpendicular to the $0^{\circ}$ yarns). The principal Young's moduli, the Poisson's ratios, and the ultimate tensile strengths were measured in these tests.

All tests were conducted in displacement control $(0.01 \mathrm{in} / \mathrm{min})$, on a 50 Kip MTS test machine. The longitudinal or axial tension specimens were 1.5 in. wide and 10.0 in. long. They had 2.25-in.-long fiberglass tabs at the ends yielding a $5.5 \mathrm{in}$. test section. The transverse tension specimens were 1.5 in. wide and $7.0 \mathrm{in}$. long. They featured 1.25 -in.-long tabs to provide a 4.5 in. long test section.

Axial and transverse strain gages were mounted on each face of the specimen at its center. A range of strain gage sizes were employed to test the sensitivity of the measurements to strain gage size. A $0^{\circ} / 90^{\circ}$ rosette gage which featured .125 in. square gages, the largest available in stock, was used on all specimens. Sizes of the gages used on the other face of the coupons varied from .062 in. to .187 in. An extensometer with a 1.0 in. gage length was also employed during each test. It was also mounted on the face of the coupon straddling the .125 in rosette gages.

Thirty-five specimens were tested in the program. Seventeen were loaded to failure to determine ultimate strength, modulus, and Poisson's ratio. Eighteen were loaded to $2000 \mu \mathrm{in} / \mathrm{in}$ of strain to measure modulus and Poisson's ratio only. Stress-strain curves recorded during the strength tests indicated that this strain level was well within the linear range for all of the braids tested.

- Results of the strength tests are summarized in Table VI. The table contains the average strengths and ultimate strains (as recorded by the extensometer) for the longitudinal (direction of $0^{\circ}$ yarns) and transverse (perpendicular to the $0^{\circ}$ yarns) tension tests. 
Table VI. Material Strength Test Results

\begin{tabular}{c|cc|cc} 
MATERIAL & \multicolumn{2}{|c|}{ LONGITUDINAL } & \multicolumn{2}{c}{ TRANSVERSE } \\
& $\begin{array}{c}\text { STRENGTH } \\
\text { (KSI) }\end{array}$ & $\begin{array}{c}\text { ULTIMATE } \\
\text { STRAIN } \\
(\%)\end{array}$ & $\begin{array}{c}\text { STRENGTH } \\
(\mathrm{KSI})\end{array}$ & $\begin{array}{c}\text { ULTIMATE } \\
\text { STRAIN } \\
(\%)\end{array}$ \\
\hline A1 & $62.6 \pm 3.7$ & $1.16 \pm .13$ & 35.3 & 0.67 \\
B1 & $80.7 \pm 1.4$ & $1.36 \pm .07$ & $41.7 \pm 3.6$ & $0.67 \pm .12$ \\
B2 & $57.1 \pm 1.7$ & $0.96 \pm .12$ & $46.5 \pm 5.7$ & $0.70 \pm .14$
\end{tabular}

Note: Data in table represents the average for three specimens.

Results of only two transverse tests on material A1 were available.

Longitudinal denotes $0^{\circ}$ yarn direction; transverse denotes perpendicular direction.

Longitudinal strengths and strains were greater than transverse strengths and strains for all three materials. In fact, transverse strengths and strains showed little sensitivity to fiber architecture. The longitudinal strengths and strains-at-failure showed a range of values, however. For example, the B2 specimens' longitudinal strength was only $20 \%$ greater than their transverse strength. The B1 specimens, by comparison, were $50 \%$ stronger in the longitudinal direction than they were in the transverse direction.

The most significant result was the difference in longitudinal strength of the $\mathrm{B} 1$ and $\mathrm{B} 2$ materials, $80.7 \mathrm{ksi}$ vs $57.1 \mathrm{ksi}$, respectively. The extent of this difference, $41 \%$, is surprizing since the materials differ so little. The specimens had comparable fiber architectures: their braid angles differed by only a few degrees; they contained comparable percentages of $0^{\circ}$ fibers. The measured fiber volumes of the two materials also showed no significant differences.

Observations of the tests and the failed specimens gave no particular insights into the failure progression. Failures were sudden, catastrophic and somewhat confined to the vicinity of the break. This last observation is more applicable to the transverse specimens than to the longitudinal specimens. Visible surface tow segments gave the appearance of behaving like small structural units that separated from each other. Fracture within tow segments was infrequent. Delaminated tows were always evident adjacent to the fracture site. However, delamination was less extensive in the transverse specimens than in the longitudinal specimens. The extent of delamination in the transverse specimens was on the order of the unit cell dimensions. Delamination in the longitudinal specimens extended over a region of two or three unit cell heights.

As indicated earlier, the three materials' Young's moduli and Poisson's ratios were also measured in these tests. The results of the longitudinal tension 
tests are summarized in Table VII. Table VIII lists the transverse tension test results.

Several general observations may be made from these data. There was little difference in the longitudinal and transverse moduli for the A1 and B1 materials. The B2 specimens' transverse modulus was slightly higher than its longitudinal modulus. In general, the longitudinal moduli data had less scatter than the transverse moduli data.

The data in the tables may also provide some insight into effective instrumentation practice for future tests. If nonuniform strain fields develop in these materials as a result of their microstructure, then the size and orientation of the gage will have a significant effect on the measured results. Assuming the nonuniformity is on the scale of the smallest unit cell, larger gages, which span larger portions of a unit cell, should have less scatter since they effectively average material response over a larger volume. Ideally, of course, the gage should span several unit cells.

In the longitudinal tests, the axial strain gages are aligned with the short dimension of the unit cells. However, even the longest gage used, 0.187 in., spanned only two unit cells. The extensometer with its $1.0 \mathrm{in}$. gage length, on the other hand, spanned several more unit cells in this direction. The general trend in the data indicates that moduli measured using the extensometer strains had less scatter than the results computed from strain gage readings.

By comparison, scatter in the transverse moduli data is larger than the scatter in the longitudinal moduli results. In the transverse direction, (the long dimension of the unit cell), the extensometer spans only about two unit cells (compared to $8-12$ in the longitudinal direction). The strain gages span less than half a unit cell and their scatter is, likewise, greater.

The longitudinal tension specimens tested were machined from six panels; two for each of the three materials. Although their fiber architectures were comparable, the B1 and B2 laminates' thicknesses varied. This was reflected in their fiber volume fractions, as noted earlier, and in their moduli. The thinner laminates which had higher fiber volumes had proportionately higher moduli.

The Poisson's ratio data may be subject to the same strain gage and unit cell size interactions suggested above. In general, the data shows that Poisson's ratio increases with strain gage size. This effect was most pronounced in the longitudinal data. The Poisson's ratio measured using .187 in. gages were 'significantly larger than those measured using .125 in. gages. 
Table VII. Longitudinal Modulus and Poisson's Ratio Measurements

\begin{tabular}{|c|c|c|c|c|c|c|c|c|c|}
\hline \multirow[t]{2}{*}{ MATERIAL } & \multirow{2}{*}{$\begin{array}{c}\text { PLATE } \\
\text { No. } \\
\end{array}$} & \multirow{2}{*}{$\begin{array}{c}\text { THICK. } \\
\text { (in.) } \\
\end{array}$} & \multicolumn{4}{|c|}{ MODULUS (MSD) } & \multicolumn{3}{|c|}{ POISSON'S RATIO } \\
\hline & & & .062 Gages & .125 Gages & .187 Gages & Extensometer & .062 Gages & .125 Gages & .187 Gages \\
\hline \multirow[t]{2}{*}{ A1 } & $15 \mathrm{~L}$ & .135 & - & $6.51 \pm .49$ & $6.51 \pm .58$ & $6.62 \pm 0.22$ & - & $.192 \pm .026$ & $.300 \pm .031$ \\
\hline & $6 \mathrm{~L}$ & .137 & 7.10 & 6.25 & - & 6.60 & .264 & .274 & - \\
\hline \multirow[t]{2}{*}{$\mathrm{B} 1$} & $2 \mathrm{~L}$ & .136 & & $6.74 \pm .68$ & $6.88 \pm .61$ & $6.55 \pm 0.25$ & - & $.176 \pm .018$ & $.268 \pm .026$ \\
\hline & $3 \mathrm{U}$ & .127 & $7.18 \pm .06$ & $7.14 \pm .21$ & - & $6.88 \pm .54$ & $.186 \pm .043$ & $.194 \pm .036$ & - \\
\hline \multirow[t]{2}{*}{ B2 } & $10 \mathrm{~L}$ & .139 & & $6.16 \pm .09$ & $6.21 \pm .32$ & $6.31 \pm .44$ & - & $.150 \pm .006$ & $.183 \pm .013$ \\
\hline & $11 \mathrm{U}$ & .124 & $6.24 \pm .27$ & $6.47 \pm .20$ & -. & $6.51 \pm .23$ & $.165 \pm .018$ & $.151 \pm .013$ & - \\
\hline
\end{tabular}

Table VIII. Transverse Modulus and Poisson's Ratio Measurements

\begin{tabular}{c|c|c|cccc|ccc} 
MATERIAL & PLATE & THICK. & \multicolumn{4}{|c|}{ MODULUS (MSI) } & \multicolumn{3}{c}{ POISSON'S RATIO } \\
& NO. & (in.) & .062 Gages & .125 Gages & .187 Gages & Extensometer & .062 Gages & .125 Gages & .187 Gages \\
\hline & & & & & & & & & \\
\\
A1 & $1 \mathrm{U}$ & .137 & 6.26 & $6.42 \pm .92$ & 6.24 & $6.59 \pm .79$ & .215 & $.275 \pm .040$ & .307 \\
$\mathrm{~B} 1$ & $\mathrm{AU}$ & .126 & $7.45 \pm 1.05$ & $6.13 \pm 1.24$ & $6.80 \pm .15$ & $6.45 \pm .35$ & $.291 \pm .022$ & $.163 \pm .031$ & $.199 \pm .012$ \\
$\mathrm{~B} 2$ & $11 \mathrm{~L}$ & .137 & $7.34 \pm 1.79$ & $7.18 \pm .88$ & $7.11 \pm .68$ & $7.03 \pm .62$ & $.161 \pm .045$ & $.181 \pm .044$ & $.190 \pm .008$
\end{tabular}

Note: Longitudinal denotes $0^{\circ}$ yarn direction; transverse denotes perpendicular direction. 


\section{MECHANICAL PROPERTY PREDICTIONS}

The ability to analytically model textile composites and predict their performance is a necessity to the efficient development of these materials and to their effective application.

Linear elastic moduli predictions were made on the basis of four different mechanical models of the various 2-D braid composites tested in the program. These models ranged from simple to complex in the manner in which they represented the fiber architecture. The purpose of this exercise was twofold. The first was to compare the predictions from the various models to each other and to experimental results. The second was to establish the level of accuracy necessary to predict the principal elastic constants of these materials for a typical preliminary design application.

\section{$\left(0^{\circ} / \theta^{\circ}\right)$ LAMINATE MODEL}

The simplest model ignores the out-of-plane undulations of the braided tows and treats each set of tows as if it were a unidirectional ply in a $(0 / \pm \theta)$ symmetric laminate. The $0^{\circ}$ longitudinal tows are considered to be the $0^{\circ}$ unidirectional plies in the laminate. The $\pm \theta$ material corresponds to the braided tows with $\theta$ as the average braid angle. When there is a significant percentage of $0^{\circ}$ tows in the construction the influence of braid tow undulations may be expected to be minimal. Figures 10 and 11 illustrate the various principal moduli estimates for $(0 / \pm \theta)$ laminate as derived from a conventional laminate analysis using the following unidirectional ply properties:

$$
\begin{array}{ll}
\mathrm{E}_{11}=18.0 \mathrm{MSI} & \mathrm{E}_{22}=1.2 \mathrm{MSI} \\
\mathrm{v}_{12}=0.3 & \mathrm{G}_{12}=0.6 \mathrm{MSI}
\end{array}
$$

where the subscripts 1,2 indicate the fiber direction and the normal to the fiber direction, respectively.

These values correspond to an AS4/epoxy composite with a fiber volume fraction of $52 \%$. Most experimental data for unidirectional AS-4 composite is in the $60-65 \%$ fiber volume fraction range. Micromechanics estimates of the appropriate corrections factors were applied to the higher fiber volume fraction data in order to obtain the $52 \%$ fiber volume fraction values. The three average experimental braid angles of $62.3^{\circ}, 67.1^{\circ}$, and $67.9^{\circ}$ are designated by the vertical lines in Figures 10 and 11 . For analysis purposes, the percentage of $0^{\circ}$ material in the figures is $34 \%$ of the total fiber content. This represents the 


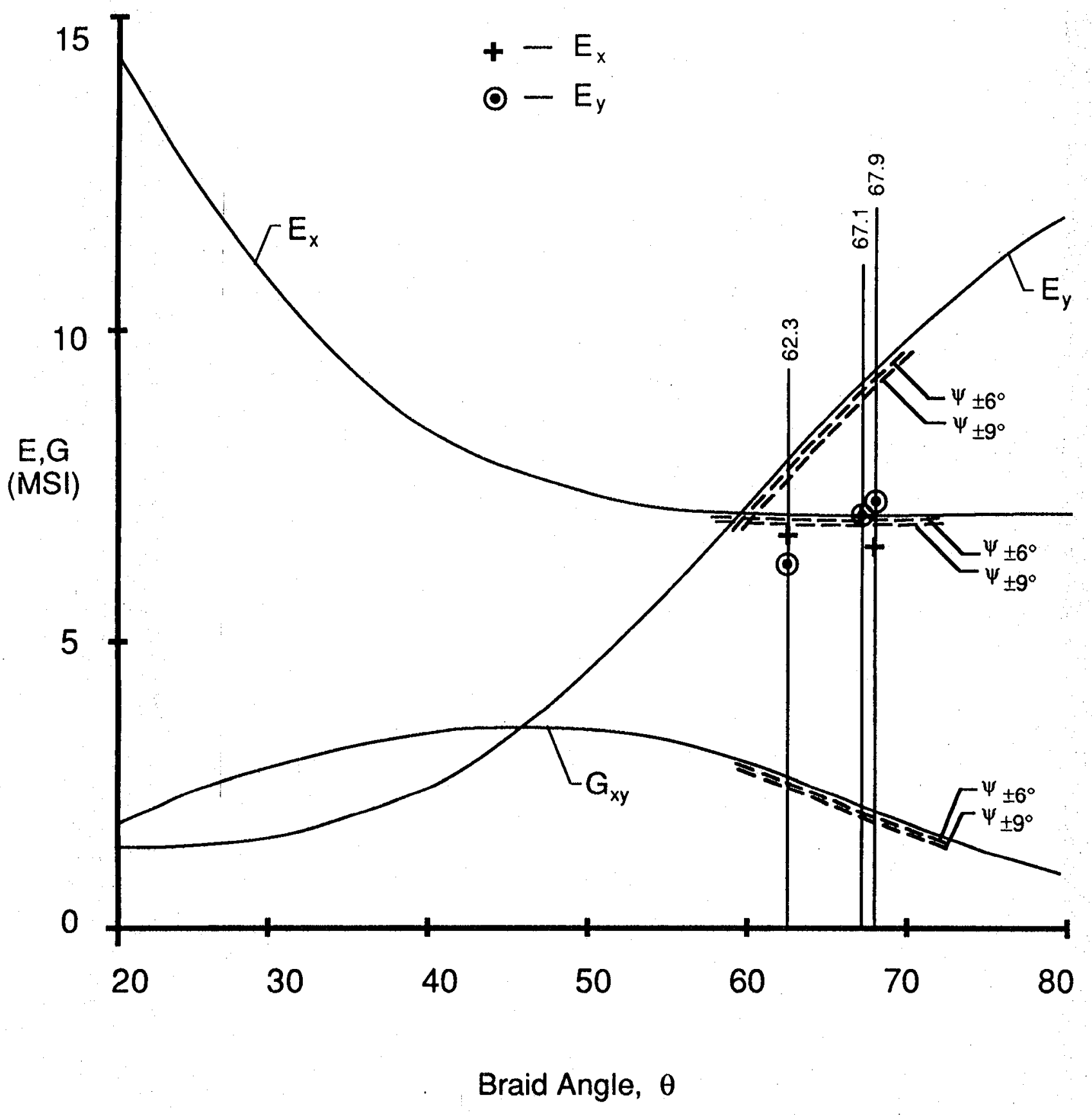

Figure 10: 2-D Braid Modulus Plots 


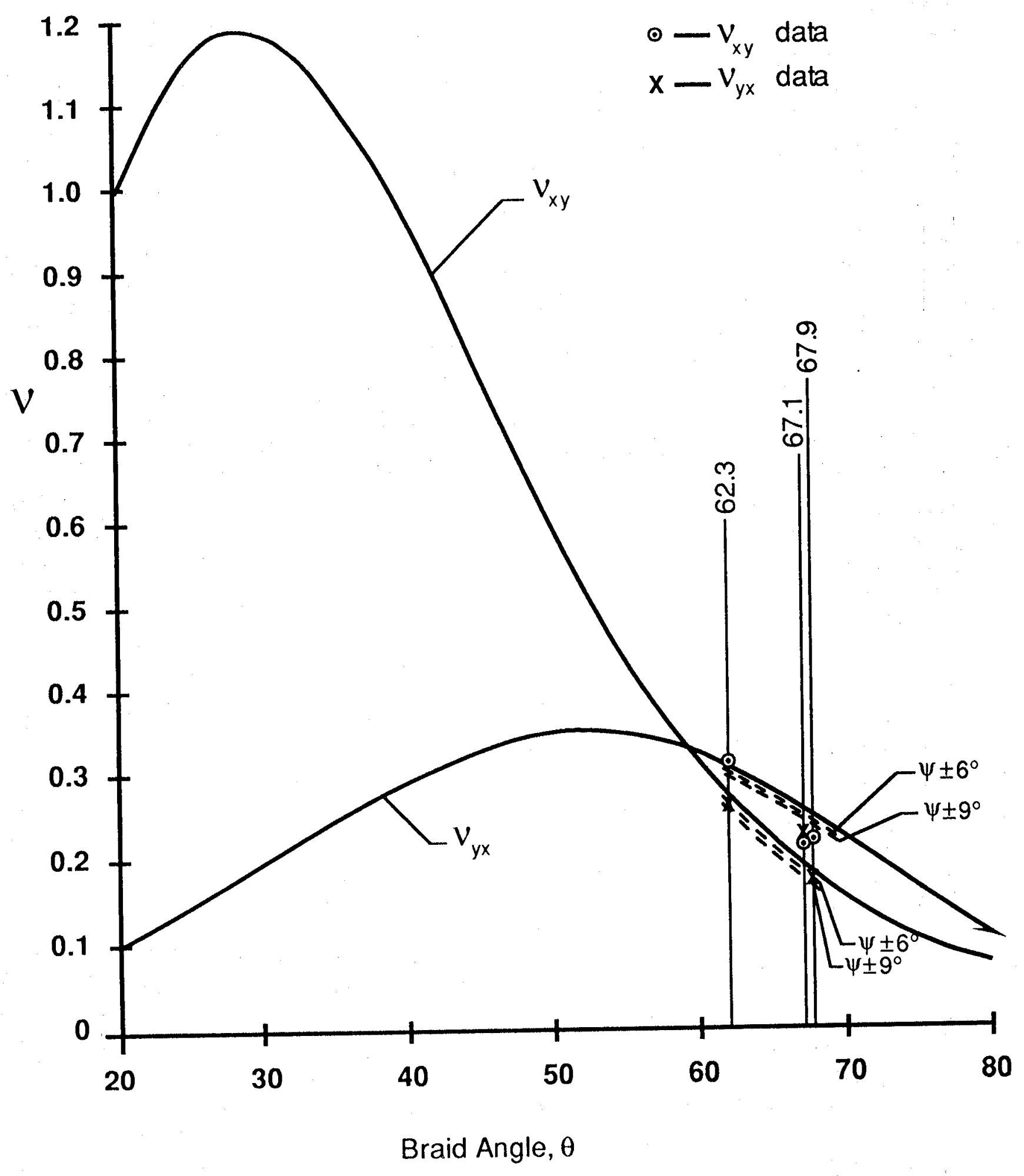

Figure 11: 2-D Braid Poisson Ratio Plots 
average for all materials investigated; measured $0^{\circ}$ yarn content ranged from $31.7 \%$ for an A1 panel to $36.8 \%$ for a B1 laminate. Deviations of the individual material averages from this overall average was not more than $\pm 2.8 \%$.

A correction factor that accounts for braid undulation can be applied to the laminate analysis. First, an average absolute value of the braid undulation angle, the average out-of-plane angle of the braid tows, $( \pm \psi)$ can be obtained by examination of the composite photomicrographs such as Figure 5. Any non-zero $\psi$ should lead to an effective reduction in the longitudinal moduli of the plies representing the two sets of braid tows. The effects on the other principal moduli of these plies should be minimal. The reduction in longitudinal moduli of these plies can be estimated by comparison of the longitudinal modulus of the unidirectional material and the $0^{\circ}$ modulus of a $\pm \psi$ symmetric laminate made from the same unidirectional material. This reduction in longitudinal modulus on the braided plies in the original laminate model leads to the corrected estimates of the $(0 / \pm \theta)$ elastic moduli shown by the dashed lines in Figures 10 and 11. The average braid undulation angles for materials $B 1$ and $B 2$ with the smaller yarns was $\pm 6^{\circ}$. Material $\mathrm{A} 1$, made from the larger tows, had a significantly higher average braid undulation angle of almost $\pm 9^{\circ}$. The corrected moduli estimates are based on these two observed average undulation angles. The symbols in the figures represent the experimental moduli measured for the three braids. The moduli computed using 0.187 in. strain gages are shown in the figure.

The $\mathrm{E}_{\mathrm{X}}$ moduli correlation, where $\mathrm{x}$ is the braid direction, was good for all three braids. The $E_{y}$ moduli correlation, where $y$ is normal to the braid direction, indicated that the analysis was consistently higher than test data. The analytical predictions of the in-plane Poisson's ratio generally followed the trend of the test data. The correction for braid undulations improved the correlation slightly.

\section{DIAGONAL BRICK MODEL}

The second mechanical model is based on the concept of the unit cell representation of the composite reinforcing microstructure. The specific model applied here consists of a brick-shaped element of bulk resin with four parallel bar elements along four edges of the brick plus four diagonal bar elements [4]. See Figure 12 for details. The edge bars represent the longitudinal yarns. The main diagonal bars represent the braided yarns. The stiffness of the bar elements (EA/L) are chosen such that they reflect the amount of fiber reinforcement within the unit cell. The dimensions of the brick are determined by the braid angle $( \pm \theta)$ and average undulation angle $( \pm \psi)$ of the braided yarns. Table IX compares the moduli predictions from the diagonal brick model with 
the predictions from the laminate models and the test data for the three different braids. Unlike the results shown in Figures 10 and 11, analytical estimates in Table IX were based on observed fiber volumes, braid angles, undulation angles, and longitudinal yarn content.

The diagonal brick model gave lower Young's moduli estimates than the corrected laminate model resulting in slightly better data correlation. The Poisson's ratio estimates were no better than the laminate analysis.

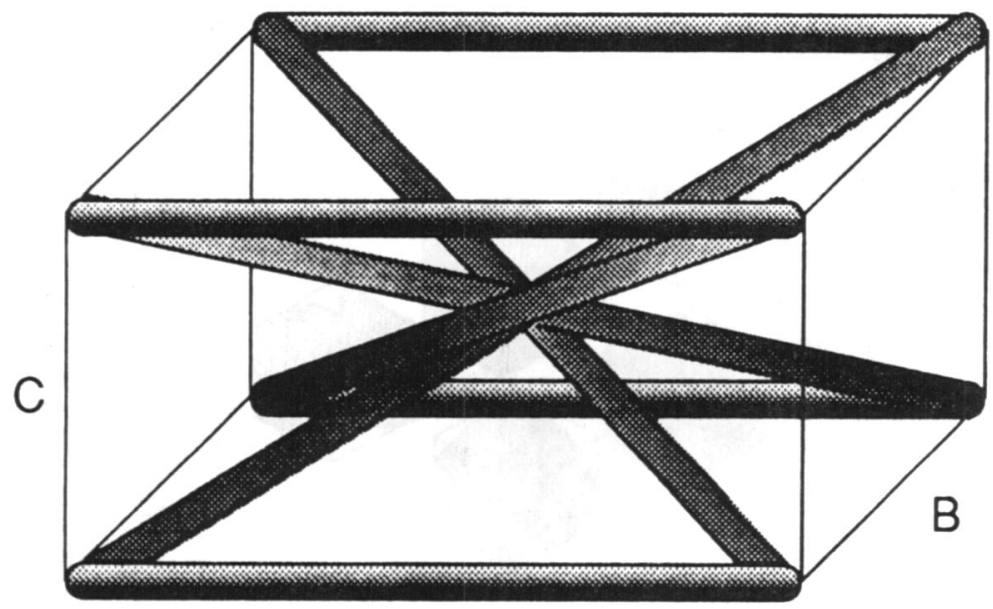

Braid angle, $\theta=\arctan \frac{\mathrm{B}}{\mathrm{A}}$ Undulation angle, $\psi=\arctan \frac{C}{A}$

A

Figure 12. Diagonal Brick Model

\section{FINITE ELEMENT MODEL}

Mechanical properties were also predicted using an analytical approach developed by one of the authors [5]. This method, which is shown schematically in Figure 13, analyzes a detailed unit cell of the reinforcing architectures in terms of sub-cells which can be combined in a finite element methodology to predict the unit cell properties. One of the advantages to this approach is that employing sub-cells of arbitrary fine size mitigates the approximation techniques associated with piecewise linear interpretation of the reinforcing geometry.

For the materials under investigation in this paper, the unit cell was constructed with the geometric model described earlier. The unit cell was divided into 9 sub-cells ( 3 elements per side) and the material properties of each sub-cell were calculated using an inhomogeneous finite element [3]. The elastic properties of the unit cell were then predicted by creating a stiffness 
matrix (K) for the structure, and solving unit displacement problems for appropriate boundary conditions.

The results of this analysis are a completed $\mathrm{K}$ matrix which can be used to derive elastic properties. For purposes of this evaluation, only $E_{x}$ and $E_{y}, v_{x y}$, and $v_{y x}$ are reported. Table IX summarizes the average predicted values for the various materials.

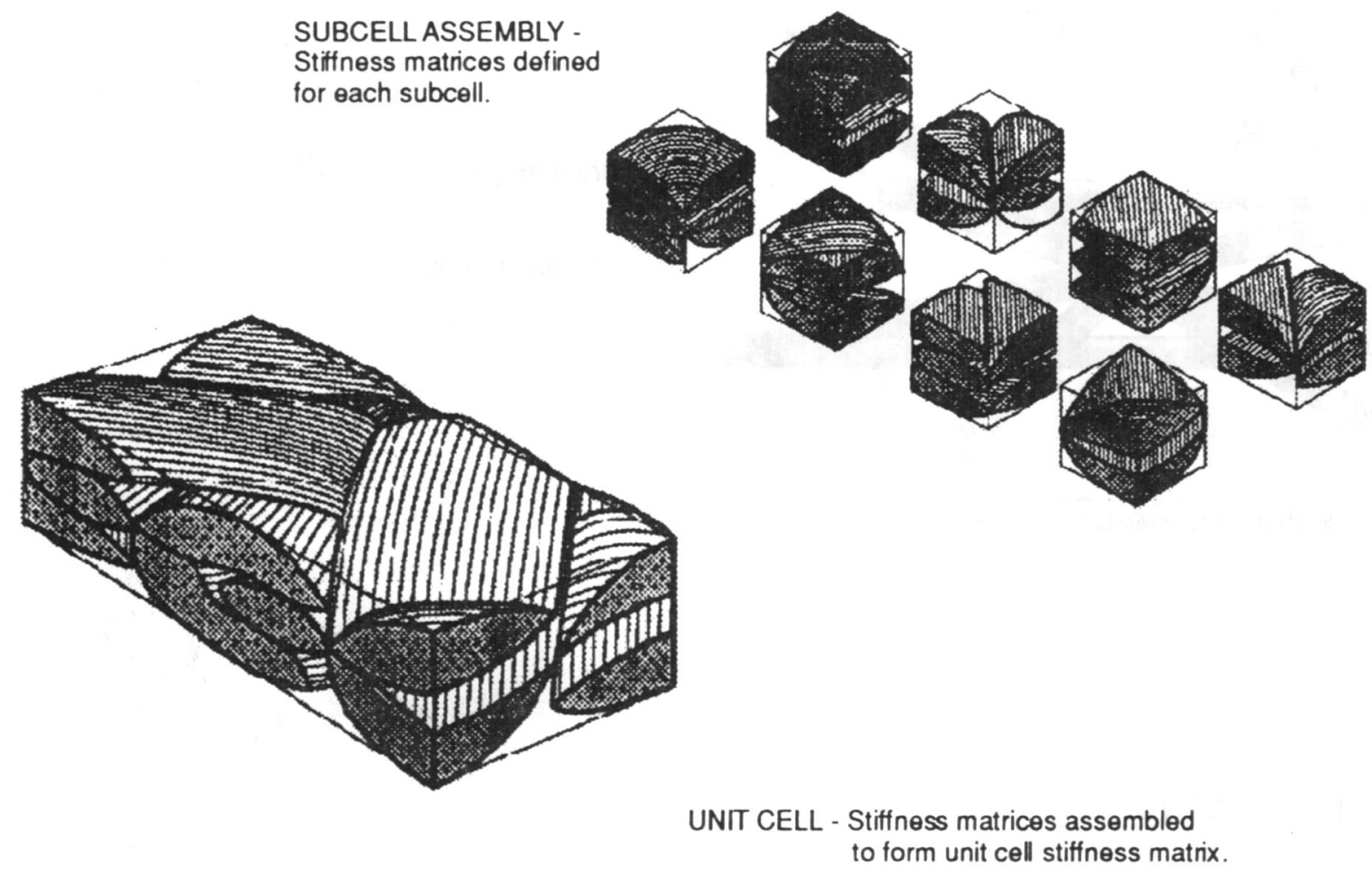

Figure 13. Schematic of Finite Element Approach.

\section{ANALYTICAL CONCLUSIONS}

In addition to tabulating the moduli and Poisson's ratios predicted by the various models, Table IX also lists the experimental results obtained using the 0.187 in. strain gages. A column of root mean square (RMS) error values is also included to provide a measure of the agreement of the experimental results to the values predicted by each analytical method.

The data indicate that all the analytical models gave consistent and accurate predictions for the Young's moduli of the three braids in the direction of the longitudinal tows. The agreement of predicted and experimental 
transverse modulus values was, however, not as good. Although the RMS values ranged from 25 to $30 \%$, inspection of the data indicates that this was due largely to the models' inability to match the modulus measured for the B1 material. Predicted and experimental results for both the A1 and the B2 materials were in much closer agreement. The reason for this discrepancy are not fully understood.

Each of the models gave reasonable approximations to the $v_{y x}$ Poisson's ratio but not the $v_{x y}$ value. Large disagreements between experimental and measured values for the Bl material again account for most of the RMS error,

In general terms, increasing the rigor with which the model represented the fiber architecture improved the agreement of predicted and experimental results. The diagonal brick model gave a better correlation to the Young's moduli than the corrected or uncorrected laminate analysis. The finite element analysis provided the closest overall agreement although the improvement was not dramatic.

The finite element analysis was marginally better in the sense of minimizing root mean square error of correlation but required more skill in application than is usually available in preliminary design. The main advantage of the finite element model is its generality. It is equally applicable to a wide variety of weaves, braids, or knits.

There is a need for improved methods of analysis and a wider range of test data with regard to braid angles, percent of longitudinal material and fiber content.

\section{SUMMARY REMARKS}

Triaxial braid reinforced composites have the potential for improved impact resistance and lower fabrication costs. However, there are problems associated with their application. Their basic design properties have not been adequately characterized. Moreover, the data that is available raises questions regarding the material behavior, the use of standard composite test methods and procedures, and the ability to predict the elastic properties.

Textile reinforced composites must be analyzed and evaluated as a structure and not a material. The fiber architecture plays a more dominant role in these materials than in unidirectional tape materials. It is, therefore, most 
important to define the fiber architecture in these composites to interpret experimental results and to form the basis of analytical models.

Table IX. Correlation of Braid Composite Properties

\begin{tabular}{|c|c|c|c|c|c|}
\hline PROPERTY & MODEL & $\begin{array}{c}\text { M A T ERI A L } \\
\mathbf{A} 1 \\
\end{array}$ & $\begin{array}{c}\text { MATERIA } \\
\text { B 1 } \\
\end{array}$ & $\begin{array}{c}\text { MATER I AL } \\
\text { B 2 } \\
\end{array}$ & $\begin{array}{r}\text { RMS } \\
\text { ERROR } \\
\end{array}$ \\
\hline Ex & EXPERIMENT & 6.62 & 6.55 & 6.31 & - \\
\hline (MSI) & LAMINATE & 6.98 & 7.22 & 6.68 & $7.5 \%$ \\
\hline & LAM. CORR. & 6.98 & 7.22 & 6.68 & $7.5 \%$ \\
\hline & DIAG. BRICK & 6.61 & 6.95 & 6.40 & $3.6 \%$ \\
\hline & FINITE ELEM. & 6.81 & 6.89 & 6.32 & $2.9 \%$ \\
\hline$E_{y}$ & EXPERIMENT & 6.59 & 6.45 & 7.03 & - \\
\hline (MSI) & LAMINATE & 7.93 & 9.49 & 7.97 & $30.1 \%$ \\
\hline & LAM. CORR. & 7.55 & 9.27 & 7.75 & $27.4 \%$ \\
\hline & DIAG. BRICK & 7.24 & 9.07 & 7.61 & $24.9 \%$ \\
\hline & FINITE ELEM. & 7.71 & 9.01 & 7.41 & $25.1 \%$ \\
\hline$v_{x y}$ & EXPERIMENT & 0.300 & 0.268 & 0.183 & - \\
\hline & LAMINATE & 0.276 & 0.166 & 0.181 & $22.5 \%$ \\
\hline & LAM. CORR. & 0.232 & 0.166 & 0.182 & $25.5 \%$ \\
\hline & DIAG. BRICK & 0.280 & 0.162 & 0.175 & $23.8 \%$ \\
\hline & FINITE ELEM. & 0.259 & 0.187 & 0.169 & $19.6 \%$ \\
\hline$v_{y x}$ & EXPERIMENT & 0.307 & 0.199 & 0.190 & - \\
\hline & LAMINATE & 0.314 & 0.218 & 0.216 & $9.7 \%$ \\
\hline & LAM. CORR. & 0.251 & 0.213 & 0.211 & $13.0 \%$ \\
\hline & DIAG. BRICK & 0.307 & 0.212 & 0.208 & $6.7 \%$ \\
\hline & FINITE ELEM. & 0.305 & 0.211 & 0.214 & $8.1 \%$ \\
\hline
\end{tabular}

Three different triaxial braids were investigated both analytically and experimentally. A process science model was used to create a three dimensional representation of the braid reinforcement. This representation was then used in conjunction with a finite element analysis to predict the materials' mechanical properties. In addition, the ability of a variety of simpler models to predict 
performance was also studied. The experimental effort consisted of a series of unnotched tension tests which were run in the two principal directions of material orthotropy.

The process science model, used in conjunction with knowledge of the braid process employed to fabricate the preforms, successfully predicted the braid architecture and the significant braid parameters such as average braid angle, fiber content, unit cell dimensions, tow spacing, and longitudinal/braid yarn ratio.

The test data indicated that the Young's moduli in the $0^{\circ}$ direction, the longitudinal direction, were stable (in the sense of varying gradually with small changes in microgeometry) and predictable by any of the common analysis methods. Tensile strength in the same direction was erratic and inexplicable. Young's modulus in the other principal direction, the transverse direction, was stable with reinforcement parameter changes but not predictable analytically. The correlation of predicted and experimental transverse modulus results was acceptable for two of the three materials studied. Strength in the transverse direction was somewhat consistent and intuitively acceptable. Poisson's ratio measurements were reasonable but failed to correlate closely with analysis in the case of contractions in the transverse direction.

The experimental results also indicate the need to carefully consider test methods and procedures in view of the unique aspects of these materials. Inhomogeneities may exist in the strain field due to the intertwining of the fibers. This places increased demand on the instrumentation. The accuracy of the strain readings, for example, is shown to be sensitive to the strain gage size. Results indicate large gage sections were preferable in the braids studied. The extensometer, with its one inch gage length, gave more consistent results than any of the smaller gages. The largest strain gages correlated best with the extensometer readings. In retrospect, significantly larger strain gage sizes and extensometer lengths seem more appropriate to this class of material.

The effects of the fiber architecture on the material response also necessitates an examination of the sizes of the specimens tested. If edge effects are on the order of the unit cell dimensions then 1.5 in. wide specimens may not be wide enough to represent the average material behavior.

The various different analysis models that were applied to the braid reinforced laminates correlated well with each other. The data indicates that the agreement between predicted and experimental values improved as the rigor in which the analyses modeled the fiber architecture increased. For example, incorporating the effect of the braided fiber crimp into the corrected 
laminated plate theory improved the agreement between predicted and measured transverse moduli. The diagonal brick model with its more detailed representation yielded even better results. The finite element model yielded the best agreements although the improvements was not large in some cases.

\section{REFERENCES}

1. Pastore, C., Gowayed, Y., and Cai, Y. J., "Application of Computer Aided Geometric Modelling for Textile Structural Composites", CADCOMP '90: Computer Aided Design in Composite Material Technology, C. Brebbia, W. de Wilde, W. Blain, Eds., Computational Mechanics Publications, Southampton, U. K., 1990.

2. ASTM D 3171 - 76 (Revised 1990) Standard Test Method for Fiber Content of Resin-Matrix Composites by Matrix Digestion. 1991 Annual Book of ASTM Standards, Volume 15, pp. 123 - 125, American Society for Testing and Materials, Philadelphia, PA.

3. Gowayed, Y. A., "An Integrated Approach to the Prediction of Mechanical and Geometric Properties of Textile Reinforced Composites", Phd Thesis North Carolina State University, Feb 1992.

4. Ma, C-L, Yang, J-M, Chou, T-W, "Elastic Stiffness of Three-Dimensional Braided Textile Structure Composites," Composite Materials: Testing and Design (Seventh Conference), ASTM 893, J. M. Whitney, Ed., American Society for Testing and Materials, Philadelphia, PA, pp 404-421.

5. Foye, R. L., "The Mechanics of Fabric Reinforced Composites", Fiber-Tex 1988, Proceedings of a conference held in Greenville, SC, Sept 13-15, 1988. Edited by J. D. Buckley, NASA Conference Publication 3038, 1989. 


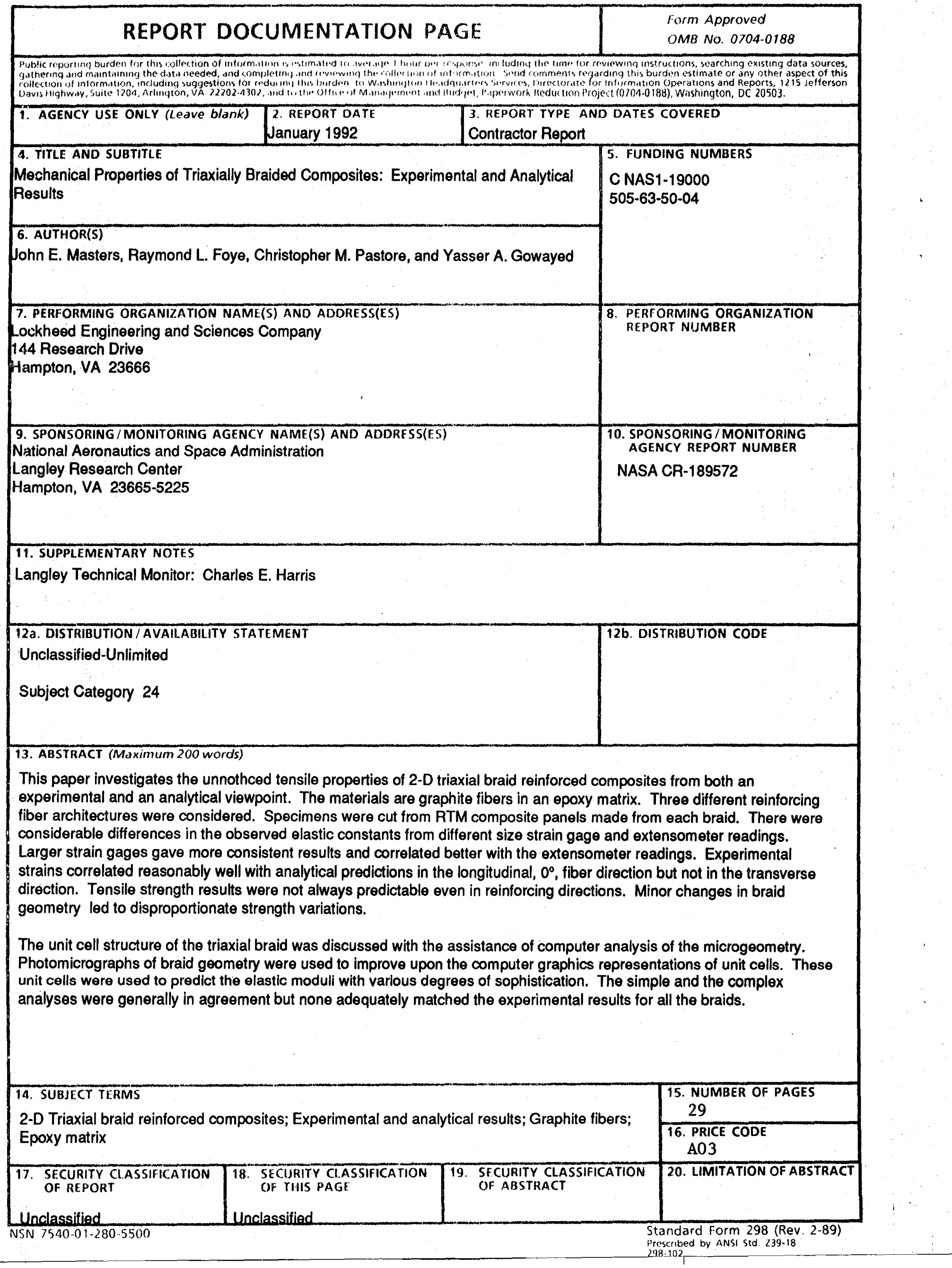


